
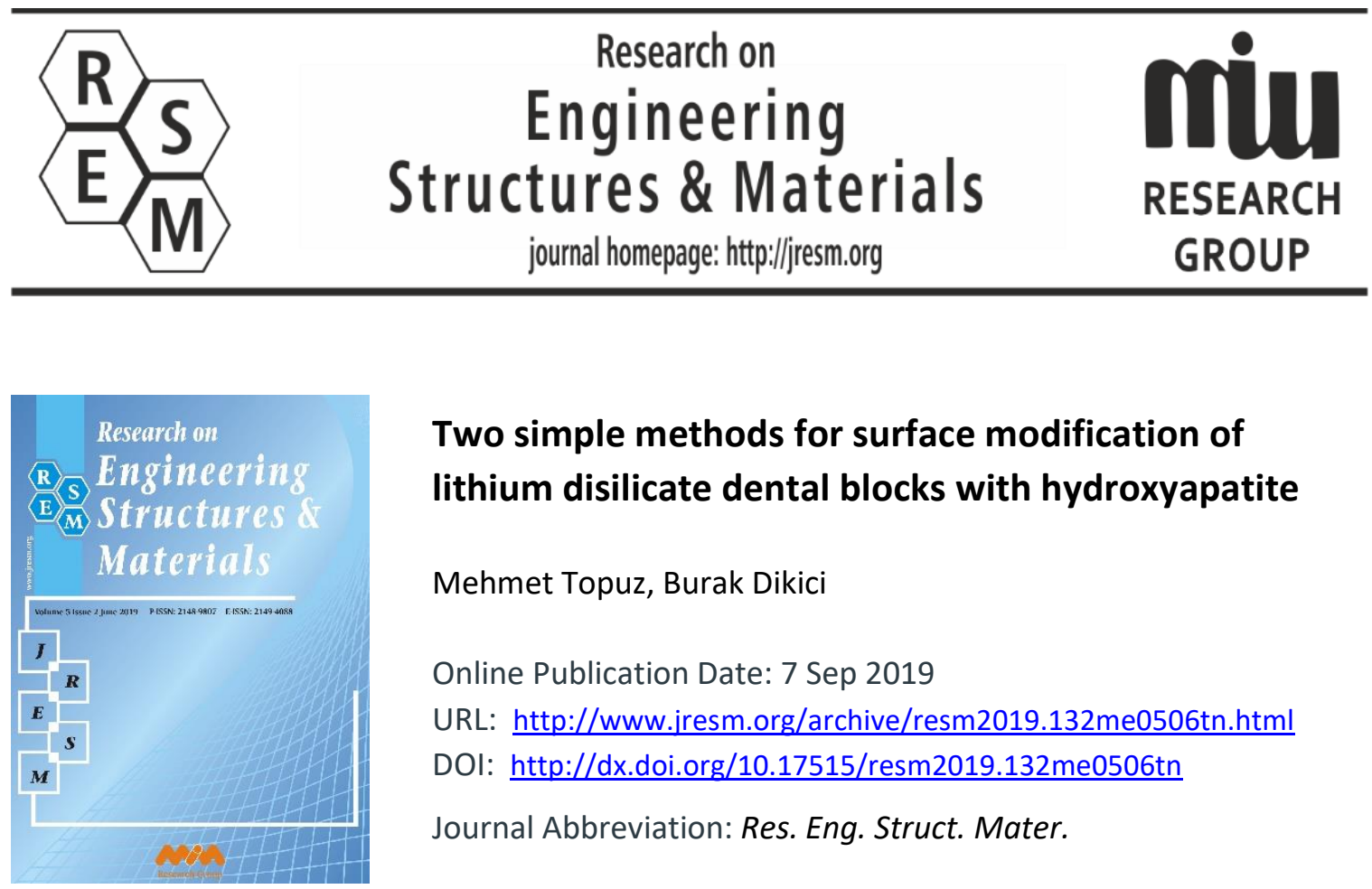

\title{
Two simple methods for surface modification of lithium disilicate dental blocks with hydroxyapatite
}

\author{
Mehmet Topuz, Burak Dikici
}

Online Publication Date: 7 Sep 2019

URL: http://www.jresm.org/archive/resm2019.132me0506tn.html

DOI: http://dx.doi.org/10.17515/resm2019.132me0506tn

Journal Abbreviation: Res. Eng. Struct. Mater.

\section{To cite this article}

Topuz M, Dikici B. Two simple methods for surface modification of lithium disilicate dental blocks with hydroxyapatite. Res. Eng. Struct. Mater., 2020; 6(1): 97-104.

\section{Disclaimer}

All the opinions and statements expressed in the papers are on the responsibility of author(s) and are not to be regarded as those of the journal of Research on Engineering Structures and Materials (RESM) organization or related parties. The publishers make no warranty, explicit or implied, or make any representation with respect to the contents of any article will be complete or accurate or up to date. The accuracy of any instructions, equations, or other information should be independently verified. The publisher and related parties shall not be liable for any loss, actions, claims, proceedings, demand or costs or damages whatsoever or howsoever caused arising directly or indirectly in connection with use of the information given in the journal or related means.

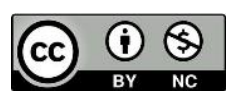

Published articles are freely available to users under the terms of Creative Commons Attribution - NonCommercial 4.0 International Public License, as currently displayed at here (the "CC BY - NC"). 


\title{
Research on Engineering Structures \& Materials \\ journal homepage: http://jresm.org
}

Technical Note

\section{Two simple methods for surface modification of lithium disilicate dental blocks with hydroxyapatite}

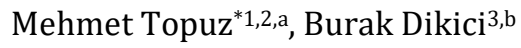 \\ ${ }^{1}$ Department of Mechanical Engineering, Van Yüzüncü Yll University, Van, Turkey \\ ${ }^{2}$ Natural and Applied Sciences, Department of Mechanical Engineering, Atatürk University, Erzurum, Turkey \\ ${ }^{3}$ Department of Metallurgical and Materials Engineering, Atatürk University, Erzurum, Turkey

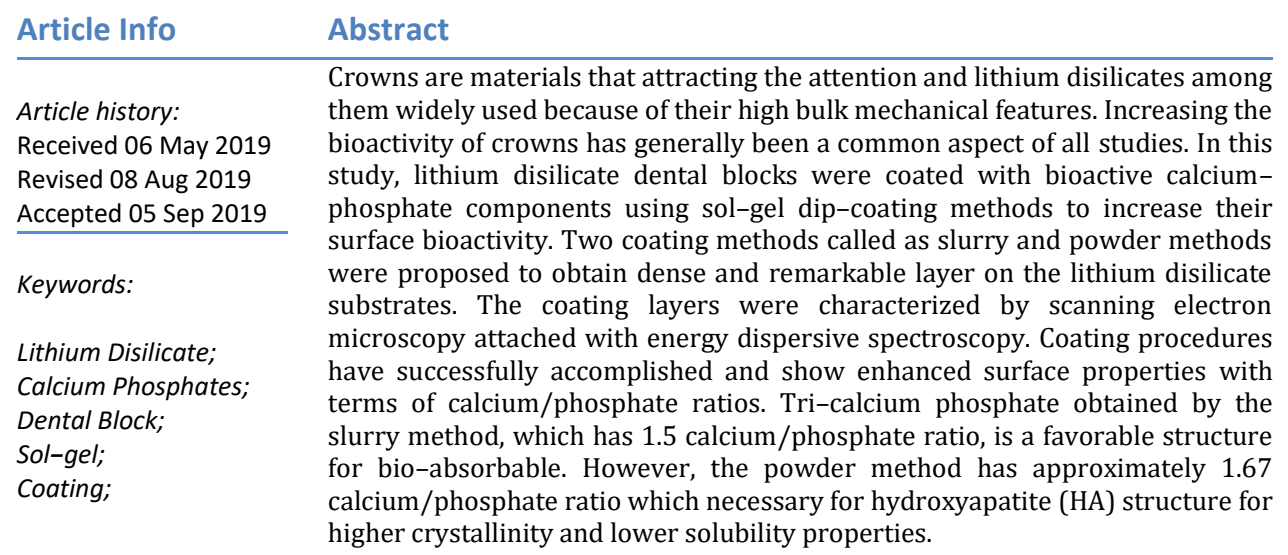

(C) 2019 MIM Research Group. All rights reserved.

\section{Introduction}

In the area of dentistry, highly detailed studies have been carried out for the restoration of the teeth that have been decaying, ageing or lost their function. As the technology progresses, always there is another innovation in the field of health. Especially in recent years, CAD/CAM technologies which have come into our lives have caused many developments in the field of dentistry. With the help of the new computer-aided image and design technology developed within this scope, it is possible to have new teeth in a short time like $40 \mathrm{~min}$ [1]. The crown is a method of restoring damaged teeth for various reasons. Crowns can be used as an implant superstructure to prevent weakened teeth from cracking, repair a broken tooth, make a bridge, overcoat a lost or deformed tooth due to excessive caries. It can be made of full-metal, metal-backed porcelain or full-porcelain. Crowns are prepared according to the model. If porcelain is used, the natural tooth tone is determined and the support adheres to the tooth [2]. Ceramic dental materials used in CAD/CAM processes are classified according to their chemical content; feldspathic, low leucite-containing glass, lithium disilicate and mica reinforced, alumina and magnesium ceramics. The lithium disilicate consists of several randomly interleaved layers. In terms of fracture resistance, the needle-like crystals prevent both cracking and divergence of the cracks [3].

\footnotetext{
*Corresponding author: mehmettopuz@yyu.edu.tr

a orcid.org/0000-0003-3692-796X; b orcid.org/0000-0002-7249-923X

DOI: http://dx.doi.org/10.17515/resm2019.132me0506tn

Res. Eng. Struct. Mat. Vol. 6 Iss. 1 (2020) 97-104
} 
On the other hand, the biggest advantage of lithium disilicate crowns is that it does not need any reinforcing elements such as metal or zirconium in its infrastructure. In other words, they are kind of a porcelain type that has been made more than 3 times more durable than classical porcelain. So, what brings us to this increase in endurance? The fact that a prosthesis can be made without the use of a substructure gives us a great advantage in mimicking the characteristic appearance of natural teeth under the light. Besides, the fact that it can be worked with thinner means that less tissue will be removed from the teeth on which it will be made. According to the location of the prosthesis to be made, dentists had to make difficult decisions to be durable or aesthetic [4].

Calcium phosphates have the ability to increase bone formation in the surrounding tissue and implanted in the human skeletal system. They are used extensively as coating components due to the higher osteoblast orientation capabilities. The apatite compound of calcium phosphates is almost identical to the mineral phase of bone and tooth, especially HA [5].

Many techniques can be used for the coating of ceramic dental blocks such as sol-gel dipcoating, plasma electrolytic oxidation and plasma spray [6-8]. However, among these techniques, sol-gel dip-coating has easier process steps and also cheaper than others.

A similar study was done on zircon blocks by Azari et al. [9] and compared thermal coating and air abrasion methods. As a result of the study, the crystalline HA structure was found in the thermal coating method while in the air abrasion method HA mini-islands were encountered. Another research conducted by Azari et al. [10], suggested that HA coatings on zirconia blocks could be a solution for increasing the adhesion strength of resin cement. In another study on bone tissue formation, it was observed that HA coatings on zircon block contributed to the formation of new bone tissue [11]. It has been stated by many researchers that there will be no problems with adhesion resistance at the abutmentcrown interface with the use of hydrofluoric acid [12,13]. However, different surfaces are being studied to investigate the living cell reaction at the interface [14]. Therefore, it has become necessary to investigate whether the bioactivity can be increased by coating lithium disilicate surfaces.

In this study, lithium disilicate dental blocks were coated with calcium phosphate components to increase their surface bioactivity. Two different coating methods (called as a slurry (LD-S) and powder (LD-P) methods) were proposed to obtain dense and remarkable layer on the lithium disilicate substrates. The synthesis steps are discussed in details, comparatively.

\section{Materials and Methods}

Lithium disilicate materials with dimensions $14.4 \times 14.4 \times 18 \mathrm{~mm}$ were used as a substrate for coating procedures (Ivocolar IPS e.max CAD). The standard structure of blocks was; 57.0-80.0\% $\mathrm{SiO}_{2}, 11.0-19.0 \% \mathrm{Li}_{2} \mathrm{O}, 0.0-13.0 \% \mathrm{~K}_{2} \mathrm{O}, 0.0-11.0 \% \mathrm{P}_{2} \mathrm{O}_{5}, 0.0-8.0 \% \mathrm{ZrO}_{2}, 0.0-8.0 \%$ $\mathrm{ZnO}, 0.0-10.0 \%$ other oxides $\left(\mathrm{Al}_{2} \mathrm{O}_{3}\right.$ and $\left.\mathrm{MgO}\right)$ and consists of $0.0-8.0 \%$ color oxides by means of weight. First of all, the samples were sandblasted by $\mathrm{Al}_{2} \mathrm{O}_{3}$ particles of $150 \mu \mathrm{m}$. The aim of sandblasting is to obtain better wettability between substrates and coating layer. Subsequently, the surface cleaning process was carried out in distilled water (DW) for $15 \mathrm{~min}$ in order to remove surface residues after sandblasting.

Two different coatings procedures (LD-S: slurry) and (LD-P: powder) were used to examine the characteristics of HA coatings synthesized on the base materials. The first one is the dipping into the slurry solution and the other is powdered and sintered HA's into a solution and the surface is coated with a dipping process. Agar was used in order to obtain a higher wettability on the surface. Synthesis of the LD-S coatings, the sol-gel method was 
used in which low sintering temperatures were sufficient, allowing complex shapes to be easily coated. In the synthesis of the sols, ethyl alcohol (Sigma-Aldrich), calcium nitrate tetrahydrate (Calcium source: $\mathrm{Ca}\left(\mathrm{NO}_{3}\right)_{2} \cdot 4 \mathrm{H}_{2} \mathrm{O}$, Sigma-Aldrich), di-ammonium hydrogen phosphate (Phosphate source: $\left.\left(\mathrm{NH}_{4}\right)_{2} \mathrm{HPO}_{2}, \mathrm{MERCK}\right)$ and agar (MERCK) were used as precursors. The amount of precursors which used for procedures was determined from the $\mathrm{Ca} / \mathrm{P}$ stoichiometric ratio of HA. $12.619 \mathrm{~g}$ of calcium nitrate tetrahydrate and $4.457 \mathrm{~g}$ of phosphorus pentoxide were dissolved in two separate $500 \mathrm{ml}$ breakers with 100 and $120 \mathrm{ml} \mathrm{DW}$, respectively. After one hour stirring $75 \mathrm{ml}$ ammonia was added to $\left(\mathrm{NH}_{4}\right)_{2} \mathrm{HPO}_{2}$ solution and stirred $10 \mathrm{~min}$ more. Then Ca solution, $1.708 \mathrm{~g}$ agar (1wt\%) was added to $\mathrm{P}$ solution slowly, and $10 \mathrm{~min}$ stirred. The mixed solution was heated until boiling and stirred $10 \mathrm{~min}$ while boiled. The boiled solution was waited in order to the aging of sol. for $24 \mathrm{~h}$. Unlike the LD-S procedure, LD-P procedure has different steps. Firstly, the slurry solution (LD-S procedures last step) filtered for 1 day to squeeze the excess amount of ammonia in the solution. Then dried in an oven at $200^{\circ} \mathrm{C}$ for $4 \mathrm{~h}$, to evaporate the residual ammonia and organic components in the wet cakes, and pulverized with the aid of a mortar. The CaP powders were sintered at $1000^{\circ} \mathrm{C}$ for $1 \mathrm{~h} .2 \mathrm{~g} \mathrm{CaP}$ powder was mixed for $2 \mathrm{~h}$ in $50 \mathrm{ml}$ DW for obtaining coating sol. After these steps, both sols were homogenized ultrasonically for $20 \mathrm{~min}$ at $25 \%$ duty rate to obtain homogenous sol. before dipping. The samples were dipcoated for three times to obtain thicker films on its, and every dip-coating steps were predried at $40^{\circ} \mathrm{C}$ for $5 \mathrm{~min}$. Finally, samples were sintered for $2 \mathrm{~h}$ at $300^{\circ} \mathrm{C}$ for $\mathrm{LD}-\mathrm{S}$ and $200^{\circ} \mathrm{C}$ for LD-P procedures. In pre-sintering trials, small burn marks on the surfaces of lithium disilicate materials were effective in the selection of sintering temperatures. In the LD-S procedure, the sintering temperature is determined as $300^{\circ} \mathrm{C}$, because the reactions between Ca and P can be occur. In the LD-P procedure, since the powders were sintered at $1000^{\circ} \mathrm{C}$ before coating, $200^{\circ} \mathrm{C}$ sintering temperature was considered sufficient. The algorithmic flow chart of both procedure is presented in Fig. 1.

Phase formations in the coatings were investigated by X-Ray diffraction (XRD, Bruker D8). XRD analyses were performed on a stage which using a radiation wavelength $\lambda=1.54056 \AA$ $\mathrm{X}$-ray source with a scan rate of $0.06^{\circ} \cdot \mathrm{s}^{-1}$ between 10 to $90^{\circ}$. Microstructural characterization of the coatings was performed using scanning electron microscopy (SEM, JEOL JSM-6335F) and energy dispersive spectroscopy (EDS, Oxford Inca). Because the coatings are ceramic-based, they were coated with $\mathrm{Au}-\mathrm{Pd}$ alloy prior to the examination to improve the image quality for SEM and EDS examinations.

\section{Results and Discussions}

SEM surface morphology and EDS result of LD-S coated samples are given in Fig. 2. When the SEM surface morphologies are examined, it is seen that there are micron-size pores in some parts of the coating structure. It is thought that these micron-sized pores formed because of the lack of surface wetting by the LD-S solution. It was also mentioned by other researchers that the nano-sized crystal structures in the pore were lithium disilicate [15]. Researchers reported that the nano-sized lithium disilicate crystals which noodles-like shaped could improve the strength of the material because of the different orientation of these crystals [3]. This situation was also determined by EDS analysis that the electron energy distribution of Si element was observed at $1.739 \mathrm{keV}$. 


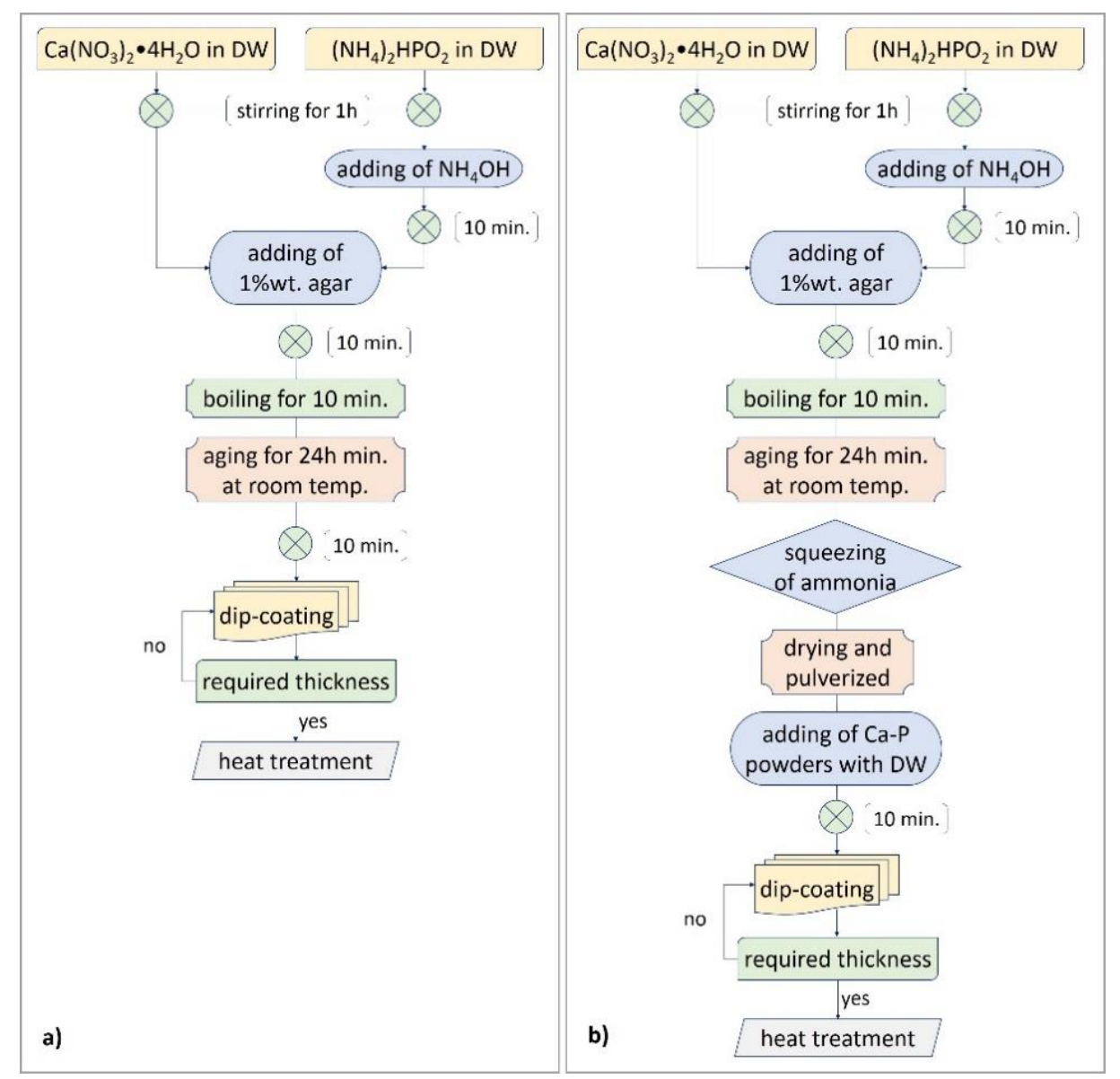

Fig. 1 Algorithmic flow charts of (a) LD-S and (b) LD-P synthesis of HA sols
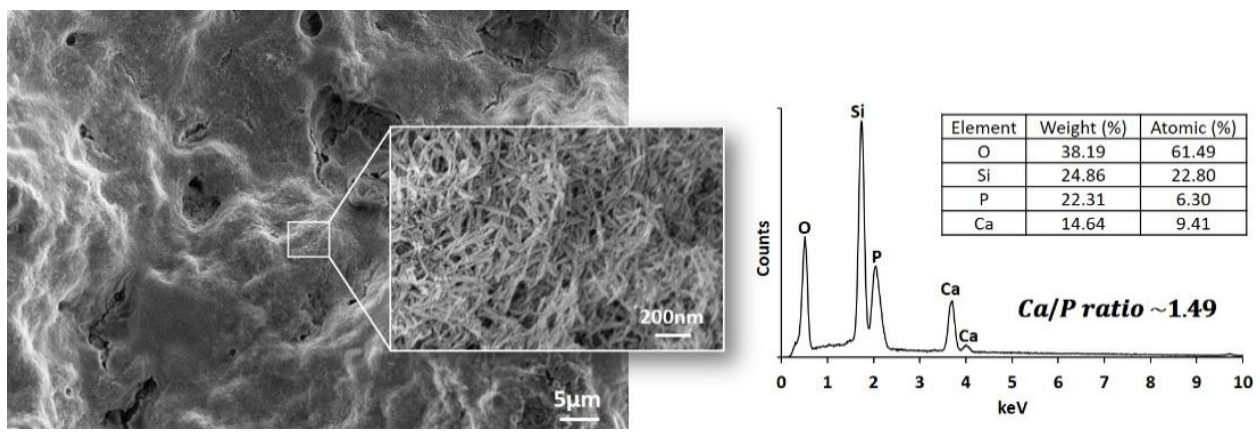

Fig. 2 SEM surface morphology of LD-S coated sample and EDS result

On the other hand, calcium and phosphate elements on the surface have been proven by EDS analysis, and the $\mathrm{Ca} / \mathrm{P}$ atomic ratio $(\sim 1.49)$ was determined to be tri-calcium phosphate ( $\beta$-TCP, $\mathrm{Ca} / \mathrm{P}$ ratio 1.5 ) [5]. It has been mentioned by many other researchers that this $\beta$-TCP structure has lower crystallinity compared to the HA structure and resulted in higher solubility but has similarly improved osseointegration properties [16]. The low $\mathrm{Ca} / \mathrm{P}$ ratio and low crystallinity values achieved may be due to the fact that coating components are made at low sintering temperatures $\left(300^{\circ} \mathrm{C}\right.$ for $\left.\mathrm{LD}-\mathrm{S}\right)$. On the other hand, 
high sintering temperatures to be used in the coating affect the long-term service life as it causes permanent damage to the substrate or changes in the grain structure.

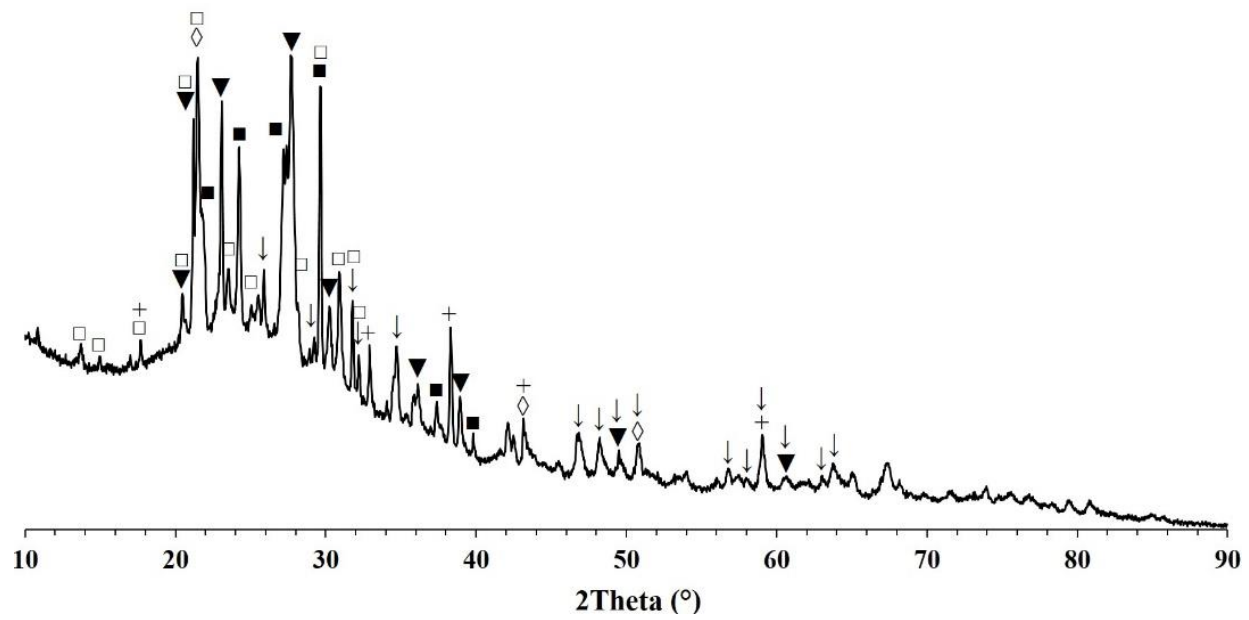

Fig. 3 XRD result of LD-S coated sample, legends are; $\downarrow \mathrm{HA}, \diamond$ Cristoballite $\left(\mathrm{SiO}_{2}\right)$, $\mathrm{Li}_{2} \mathrm{Si}_{2} \mathrm{O}_{5}, \boldsymbol{\nabla}$ Trdymite $\left(\mathrm{SiO}_{2}\right),+\mathrm{Li}_{2} \mathrm{SiO}_{3}, \square \beta-\mathrm{TCP}$

XRD analyze of LD-S coated samples was given in Fig. 3. As shown from XRD result of LD-S sample, $\beta$-TCP structure was confirmed with 09-0348 JCPDS card number. This result agrees with EDS analyze result. LD-S coated samples show small amount of HA peaks (090432 ) which may be observed as it is sintered at the $\beta$-TCP-HA transition temperature. On the other hand, different phases such as Cristoballite $\left(\mathrm{SiO}_{2}\right)$, Trdymite $\left(\mathrm{SiO}_{2}\right), \mathrm{Li}_{2} \mathrm{Si}_{2} \mathrm{O}_{5}$ and $\mathrm{Li}_{2} \mathrm{SiO}_{3}$ were found from the base material (JCPDS card numbers are; 01-0424, 01-0378, 040-0376 and 010-0017 respectively). It is thought that phases which contain lithium and silicate come from the substrate materials, due to the inhomogeneous surface morphology of the coating.
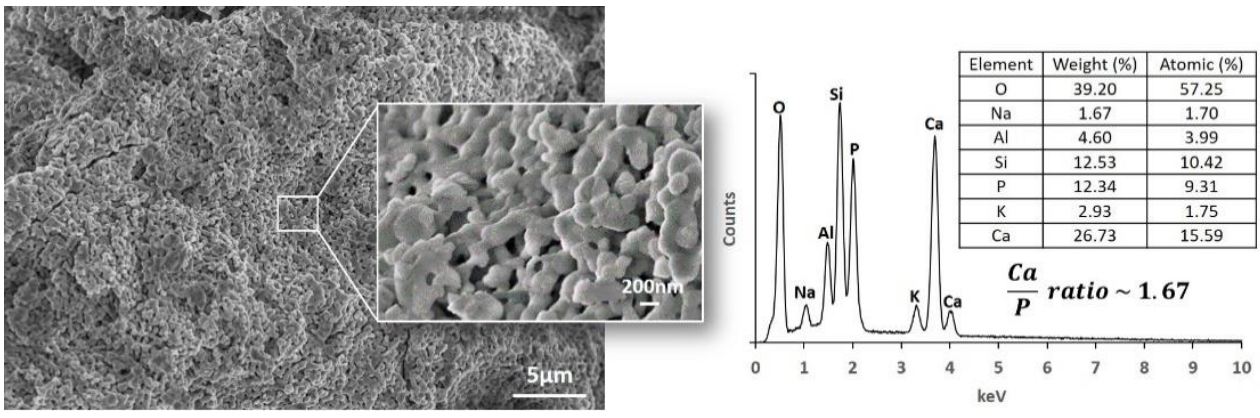

Fig. 4 SEM surface morphology of LD-P coated sample and EDS result

The SEM surface morphology and EDS results of the coating synthesized by the LD-P method are shown in Fig. 4. It can be shown that from Fig. 4 the surface is smoother than LD-S and has nano-sized pores. These nano-sized pores may responsible for enhanced biocompatibility. Unlike the LD-S method, the $\mathrm{Ca} / \mathrm{P}$ ratio was measured as 1.67 in this method, atomically. In order to determine whether HA which another calcium phosphate structure is formed, the researchers decide either the $\mathrm{Ca} / \mathrm{P}$ ratio or the XRD test. As it is known from the literature, the $\mathrm{Ca} / \mathrm{P}$ ratio of $\mathrm{HA}$ is 1.67 and it is the same as the value obtained in this method $[17,18]$. It was determined that the $\mathrm{Na}, \mathrm{Si}$, and $\mathrm{K}$ elements of the 
EDS results from the blocks which used as substrate material [2], Al element was determined due to the blasting process applied before the coating. The high crystallinity of the HA shows that it will not dissolve easily and have a long life in the physiological environment. The surfaces similar to the surface of the LD-P were also obtained by other researchers $[19,20]$.

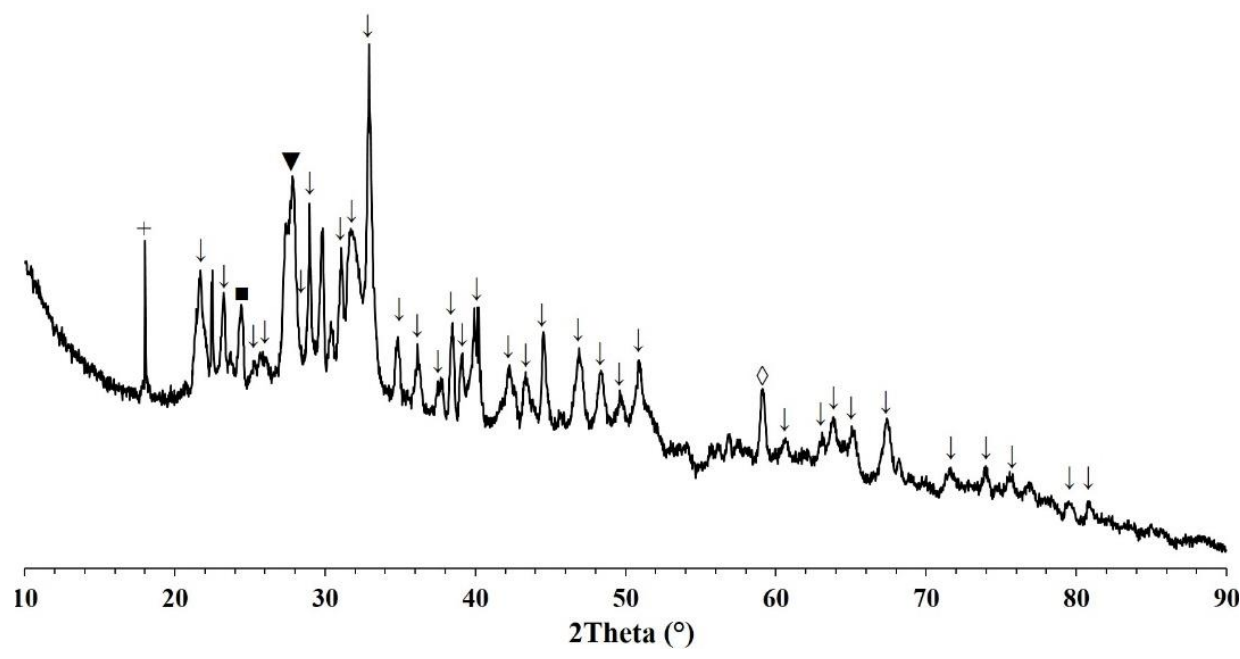

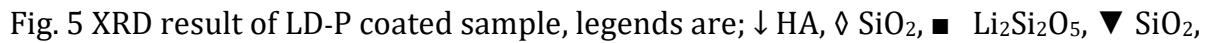
$+\mathrm{Li}_{2} \mathrm{SiO}_{3}$

Phase formations and transformations (XRD result) of LD-P coated samples are presented in Fig. 5. These results were in agreement with SEM/EDS results. When compared with XRD results of LD-S samples, it is seen that XRD peak widths of LD-P samples are narrower and this may be caused by pre-sintering process applied in LD-P method. Unlike LD-S method's XRD result, LD-P coated sample has completely HA phases on it.

Findings from the studies emphasized that agar causes Ca deficiency in HA structure [21]. Ouyang et al. [22] were found that the amount of agar decreased to about $30 \%$ by weight, but not completely decomposed by heat treatment at $300^{\circ} \mathrm{C}$. The difference in $\mathrm{Ca} / \mathrm{P}$ ratios between LD-S and LD-P procedures is thought to be due to the agar's removal from the coating composition after $1000^{\circ} \mathrm{C}$ of heat treatment for powdering in the LD-P procedure. As can be seen from the researches, the sintering temperature of the LD-S procedure was $300^{\circ} \mathrm{C}$, did not completely decompose the agar from the coating composition. Thus, it is evident that a small amount of agar remaining in the coating composition leads to Ca deficiency and a low $\mathrm{Ca} / \mathrm{P}$ ratio. Besides SEM/EDS analyses, phenomenon which formation of both $\beta$-TCP and HA, proved by XRD results. $\mathrm{Li}_{2} \mathrm{Si}_{2} \mathrm{O}_{5}$ was major phase from substrate materials but there is a small amount of $\mathrm{SiO}_{2}$ and $\mathrm{Li}_{2} \mathrm{SiO}_{3}$ peaks which may occur nucleation of Li and Si during sintering. It's thought that such higher intensities, as can be seen in XRD results, are favorable to human body due to the lower soluble behavior.

Also, as Narayanan et al. [23] mentioned, $\beta$-TCP stated that it could be absorbed in the body and HA could not be absorbed. While absorption in the body is a more important condition, due to the unpredictable dissolution behavior of $\beta$-TCP, HA which has high stability properties, is more desirable. After all these results and discussions, the LD-P procedure is thought to be an alternative coating procedure for lithium disilicate ceramics due to its HA structure and surface homogeneity. HA formation on LD-P coated samples were proved by $\mathrm{XRD}$ results. In addition, it is thought to have a positive effect on cell growth at the 
abutment-crown interface with its optimal $\mathrm{Ca} / \mathrm{P}$ ratio and will not cause any adverse reactions.

\section{Conclusion}

In this study, lithium disilicate blocks used in the field of dentistry were investigated by using two different methods and their ability to form a possible calcium phosphate component was investigated. The coatings obtained in the LD-P method were found to be more preferable both as surface morphologies and $\mathrm{Ca} / \mathrm{P}$ ratio. In the literature, there are a few studies which conducted on surface morphologies of HA coatings on lithium disilicates but it is suggested that osteoconductivity or osteoblast formability tests of the coatings synthesized by both methods will be made and investigated in the future.

\section{References}

[1] Liu P-R. A Panorama of dental CAD/CAM restorative systems. Compendium of continuing education in dentistry. 2005;29(7):507-512.

[2] Figueiredo-Pina CG, Patas N, Canhoto J, Claudio R, Olhero SM, Serro AP, Ferro AC, Guedes M. Tribological behaviour of unveneered and veneered lithium disilicate dental material. Journal of the Mechanical Behavior of Biomedical Materials. 2016;53:226238. http://dx.doi.org/10.1016/j.jmbbm.2015.08.007

[3] Ural Ç. Diş Hekimliği Pratiğinde Tamamı Seramik ve Cad-Cam Uygulamaları. Dirim Tip Gazetesi. 2011;86:27-38.

[4] Tysowsky G. The Science Behind Lithium Disilicate: Today's Suprisingly Versatlie, Esthetic \& Durable Metal-Free Alternative. Oral Health. 2009;99(3):93-97.

[5] Topuz M. Production of Bioactive Hybrid Coatings on Beta $(\beta)$-Type Titanium Alloys, Characterization and Investigation of In-vitro Corrosion Properties, Ms Thesis, Yüzüncü Yll University, Van, Turkey, 51-52, 2016.

[6] Dikici B, Niinomi M, Topuz M, Say Y, Aksakal B, Yılmazer H, Nakai M. Synthesis and characterization of hydroxyapatite/TiO2 coatings on the $\beta$-type titanium alloys with different sintering parameters using sol-gel method. Protection of Metals and Physical Chemistry of $\quad$ Surfaces. 2018;54(3):457-462. https://doi.org/10.1134/S2070205118030255

[7] Songur F, Dikici B, Niinomi M, Arslan E. The plasma electrolytic oxidation (PEO) coatings to enhance in-vitro corrosion resistance of Ti-29Nb-13Ta-4.6Zr alloys: The combined effect of duty cycle and the deposition frequency. Surface and Coatings Technology. 2019;374:345-354. https://doi.org/10.1016/i.surfcoat.2019.06.025

[8] Xu H, Geng X, Liu G, Xiao J, Li D, Zhang Y, Zhu P, Zhang C. Deposition, nanostructure and phase composition of suspension plasma-sprayed hydroxyapatite coatings. Ceramics International. 2016;42(7):

8684-8690. https://doi.org/10.1016/j.ceramint.2016.02.102

[9] Azari A, Jamnani SN, Yazdani A, Atri F, Rasaie V, Yazdi AFA. Deposition of Crystalline Hydroxyapatite Nanoparticles on Y-TZP Ceramic: A Potential Solution to Enhance Bonding Characteristics of Y-TZP Ceramics. Journal of Dentistry (Tehran). 2017;14(2):62-68.

[10] Azari A, Nikzad S, Yazdani A, Atri F, Yazdi AFA. Deposition of crystalline hydroxyapatite nano-particle on zirconia ceramic: a potential solution for the poor bonding characteristic of zirconia ceramics to resin cement. Journal of Materials Science: Materials in Medicine. 2017;28(7). https://doi.org/10.1007/s10856-017$\underline{5921-8}$

[11] Hirota M, Hayakawa T, Ohkubo C, Sato M, Kara H, Toyama T, Tanaka Y. Bone responses to zirconia implants with a thin carbonate-containing hydroxyapatite coating using a 
molecular precursor method. Journal of Biomedical Materials Research - Part B Applied Biomaterials. 2014;102(6):1277-1288. https://doi.org/10.1002/jbm.b.33112

[12] Lanza MDS, Lanza FJSR, Manso AP, Matinlinna JP, Carvalho RM. Innovative surface treatments for improved ceramic bonding: Lithium disilicate glass ceramic. International Journal of Adhesion and Adhesives. 2018;82:60-66. https://doi.org/10.1016/j.ijadhadh.2017.12.007

[13] Prochnow C, Pereira GKR, Venturini AB, Scherer MM, Rippe MP, Bottino MC, Kleverlaan CJ, Valandro LP. How does hydrofluoric acid etching affect the cyclic loadto-failure of lithium disilicate restorations. Journal of the Mechanical Behavior of Biomedical Materials.

2018;87:306-311. https://doi.org/10.1016/j.jmbbm.2018.07.040

[14] Mehl C, Kern M, Schütte A-M, Kadem LF, Selhuber-Unkel C. Adhesion of living cells to abutment materials, dentin, and adhesive luting cement with different surface qualities. Dental Materials.

2016;32(12):1524-1535. https://doi.org/10.1016/i.dental.2016.09.006

[15] Küçük BE, Kunt GE. Lityum Disilikat Seramikler. Atatürk University Journal of Dentistry Faculty. 2012;5:123-131.

[16] Zhang J, Iwasa M, Kotobuki N, Tanaka T, Hirose M, Ohgushi H. Fabrication of hydroxyapatite-zirconia composites for orthopedic applications. Journal of the American Ceramic Society. 2006;89(11):3348-3355. https://doi.org/10.1111/j.15512916.2006.01237.x

[17] Janković A, Eraković S, Mitrić M, Matić IZ, Juranić ZD, Tsui GCP, Tang C, MiskovićStanković V, Rhee KY, Park SJ. Bioactive hydroxyapatite/graphene composite coating and its corrosion stability in simulated body fluid. Journal of Alloys and Compounds. 2015;624:148-157. https://doi.org/10.1016/j.jallcom.2014.11.078

[18] Dikici B, Niinomi M, Topuz M, Koç SG, Nakai M. Synthesis of biphasic calcium phosphate (BCP) coatings on $\beta$-type titanium alloys reinforced with rutile-TiO2 compounds: adhesion resistance and in-vitro corrosion. Journal of Sol-Gel Science and Technology. 2018;87(3):713-724. https://doi.org/10.1007/s10971-018-4755-2

[19] Karamian E, Khandan A, Kalantar Motamedi MR, Mirmohammadi H. Surface characteristics and bioactivity of a novel natural HA/zircon nanocomposite coated on dental implants. BioMed Research International. 2014;2014:1-10. http://dx.doi.org/10.1155/2014/410627

[20] Pardun K, Treccani L, Volkmann E, Streckbein P, Heiss C, Destri GL, Marletta G, Rezwan K. Mixed zirconia calcium phosphate coatings for dental implants: Tailoring coating stability and bioactivity potential. Materials Science and Engineering C. 2015;48:337346. https://doi.org/10.1016/i.msec.2014.12.031

[21] Deng Y, Wang H, Zhang L, Li Y, Wei S. In situ synthesis and in vitro biocompatibility of needle-like nano-hydroxyapatite in agar-gelatin co-hydrogel. Materials Letters. 2013;104:8-12. https://doi.org/10.1016/j.matlet.2013.03.145

[22] Ouyang Q-Q, Hu Z, Li S-D, Quan W-Y, Wen L-L, Yang Z-M, Li P-W. Thermal degradation of agar: Mechanism and toxicity of products. Food Chemistry. 2018;264(March);277283. https://doi.org/10.1016/j.foodchem.2018.04.098

[23] Narayanan R, Seshadri SK, Kwon TY, Kim KH. Calcium phosphate-based coatings on titanium and its alloys. Journal of Biomedical Materials Research - Part B Applied Biomaterials. 2008;85(1):279-299. https://doi.org/10.1002/jbm.b.30932 